\title{
Correlation between C-reactive Protein Levels with Cognitive Function and Body Mass Index in Schizophrenia
}

\author{
M. Putra Mahmuddin*, Elmeida Effendy (D), Mustafa M Amin (D) \\ Department of Psychiatry, Faculty of Medicine, University of North Sumatra, Medan, Indonesia
}

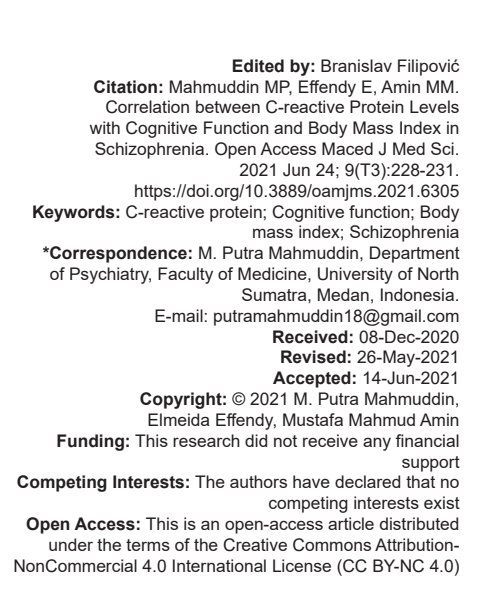

Abstract

AIM: The objectives of the study were to determine the correlation between C-reactive protein (CRP) levels with cognitive function and body mass index (BMI) in a patient with schizophrenia.

METHODS: This is a numerical correlative analytic study with a cross-sectional approach by means of nonprobability sampling with consecutive sampling with inclusion and exclusion criteria from August 2019 to November 2019 in the Prof. Dr. M. Ildrem Psychiatric Hospital in Province of North Sumatra after getting approval from the Research Ethics Committee at the Faculty of Medicine, University of North Sumatra.

RESULTS: There is a very strong correlation in which Pearson correlation test between the high-sensitivity CRP (HsCRP) value with BMl and the Montreal cognitive assessment Versi Indonesia score in schizophrenic patients with a correlation coefficient value of $r=0.951$ and $r=-0.743$, respectively, with a very strong correlation $(p<0.001)$.

CONCLUSIONS: Increased pro-inflammatory activity, especially HsCRP may cause impaired cognitive function in people with schizophrenia.

\section{Introduction}

Schizophrenia is a variable clinical syndrome in which psychopathology involving cognition, emotion, perception, and other aspects of behavior [1]. The prevalence of schizophrenia cases is approximately $1 \%$, usually starting at age 25 , persists throughout life, and affects people of all social classes. Both patients and their relatives experience social problems from society due to great ignorance of the disease [2].

Schizophrenia still has unclear etiology causing it as a serious neuropsychiatric disorder. Besides genetic factors, infection and inflammatory processes have been identified as potential contributing factors to the etiology and pathogenesis of the disease [3]. Several inflammatory processes are also thought to be associated with schizophrenia [4]. Inflammation may be important in the general pathophysiological processes associated with both the pathophysiological state of schizophrenia and the metabolic disorders in people with schizophrenia [5].

C-reactive protein (CRP), an inflammatory marker derived from the liver associated with metabolic disease in response to an immune marker in acute phase activated by pro-inflammatory cytokines and secreted by hepatocytes. Several previous studies have found that inflammatory CRP reaction may be related to schizophrenia, wherein the study found that serum CRP levels were clinically elevated schizophrenic people [3], [6], [7], [8].

Schizophrenic patients may be in risk of being overweight or obese due to a collection of clinical, physiological, psychosocial, environmental factors, and possibly additional genetic factors. The negative symptoms of schizophrenia, such as apathy and social withdrawal, as well as poverty, were thought to have contributed to the sedentary lifestyle and poor diet of this patient population [9]. There are several possible causes of increased obesity among schizophrenic patients. It has been suggested that poor eating habits, lifestyle, and antipsychotic medication may lead to weight gain among patients with schizophrenia, causing obesity which is associated with morbidity and mortality [10].

From the description above, which there is often an increase in CRP in people with schizophrenia and a cognitive decline in an increase in CRP levels, researchers need to conduct research to determine the correlation between CRP levels with cognitive 
function and body mass index (BMI) in people with schizophrenia.

\section{Methods}

\section{Patient sample}

This is a numerical correlative analytic study with a cross-sectional approach, which the subject is taken by means of nonprobability sampling by consecutive sampling at the Prof. Dr. M. Ildrem Psychiatric Hospital in Province of North Sumatra from August 2019 to November 2019. The inclusion criteria include (1) people with schizophrenia who have been diagnosed based on PPDGJ III; (2) aged between 15 and 50 years; (3) schizophrenic patients using the drug risperidone with a treatment period of 1 year; (4) willing as a respondent and can be interviewed. The exclusion criteria were (1) a history of alcohol and other substance use; (2) patients who have a history of metabolic disease, vascular disease, and neurological disease. All research subjects had filled in written consent to participate in the study after getting approval from the Research Ethics Committee at the Faculty of Medicine in University of North Sumatra. BMI was obtained by measuring body weight and height, and blood samples were taken, which the patient has been fasting for at least $8 \mathrm{~h}$ before, and blood collection was carried out in the morning at 08.00-09.00 WIB, as much as 3cc from the median cubital vein to obtain the levels of CRP. Then, an assessment and calculation of the Montreal cognitive assessment Versi Indonesia (MoCA-INA) were carried out.

\section{Statistical analysis}

The analysis of the data collected was carried out using a software program statistical package for service solutions (SPSS ver 22). Before data analysis, a data normality test will be performed using the Kolmogorov-Smirnov test if the number of subjects is more than 50 and the Shapiro-Wilk test if the subjects are $<50$. If the data are normally distributed, data analysis will be carried out using the Pearson correlation test. Otherwise, the data analysis is performed using the Spearman correlation test.

\section{Results}

The demographic characteristics are presented in Table 1. Before the correlation test was carried out, the normality test was first carried out on
Table 1: Demographic characteristics

\begin{tabular}{|c|c|c|c|}
\hline Variable] & Standard deviation & $\mathrm{n}(\%)$ & $\mathrm{p}$ \\
\hline \multicolumn{4}{|l|}{ Gender } \\
\hline Men & & $24(58.5)$ & \\
\hline Women & & $17(41.5)$ & \\
\hline Age (years) & $31.49 \pm 5.17^{*}$ & & 0.682 \\
\hline \multicolumn{4}{|l|}{ Education } \\
\hline High school & & $31(75.6)$ & \\
\hline Bachelor & & $10(24.4)$ & \\
\hline \multicolumn{4}{|l|}{ Marital status } \\
\hline Married & & $22(53.7)$ & \\
\hline Single & & $19(46.3)$ & \\
\hline \multicolumn{4}{|l|}{ Profession } \\
\hline Work & & $14(34.1)$ & \\
\hline Not yet working & & 27 (65.9) & \\
\hline Long Sick & $5.95 \pm 1.78$ * & & 0.144 \\
\hline
\end{tabular}

the data where the high-sensitivity CRP (HsCRP) level and $\mathrm{BMI}$ variables were tested for distribution normality using the Shapiro-Wilk test, and the HsCRP levels and BMI variables were distributed. Normal. Therefore, the data correlation test was performed using the Pearson correlation test (Table 2).

Table 2: The correlation between the HsCRP value and BMI

\begin{tabular}{lllll}
\hline Variable & Average & Standard deviation & $\mathrm{p}$ & $\mathrm{r}$ \\
\hline HsCRP & 5.23 & \pm 2.23 & & \\
BMI & 22.65 & \pm 1.74 & $<0.001$ & 0.951 \\
\hline HsCRP: High-sensitivity C-reactive protein, BMI: Body mass index, Pearson correlation test. &
\end{tabular}

The results of the correlation test showed that there was a correlation between the HsCRP variable and the BMI variable with a $p<0.001$ ( $p<0.05$ ), so it could be seen that there was a very significant correlation between the HsCRP value and the BMI. The strength of the relationship between the HsCRP value and $\mathrm{BMI}$ is 0.951 , indicating that the correlation between the HsCRP variable and the $\mathrm{BMI}$ variable is very strong $(r>0.8)$ and is positive, which means that as the HsCRP value increases, the BMl will also be increasing (Table 3).

Table 3: Correlation between the HsCRP value and the MoCA-INA score

\begin{tabular}{lllll}
\hline Variable & Average & Standard deviation & $\mathrm{p}$ & $\mathrm{r}$ \\
\hline HsCRP & 5.23 & \pm 2.23 & & \\
MoCA-Ina Score & 21.20 & \pm 2.70 & $<0.001$ & -0.743 \\
\hline HsCRP: High-sensitivity C-reactive protein, MoCA-INA: Montreal cognitive assessment Versi Indonesia.
\end{tabular}

Pearson's correlation test shows that there is a correlation between the HsCRP variable and the MoCA-INA score variable with a $p<0.001$ ( $p<0.05$ ), so there is a very significant correlation between the $\mathrm{HsCRP}$ value and the MoCA-INA score. The correlation between the HsCRP value and the MoCA-INA score is -0.743 , indicating that the correlation between the HsCRP variable and the MoCA-INA score variable is strong $(0.6<p<0.8)$ and is negative, which means, as the HsCRP value increases, then the MoCA-INA score will decrease.

\section{Discussion}

In this study, it was found that based on the Pearson correlation test, the HsCRP was significantly 
correlated with the BMI with a $p<0.001$ and $r=0.951$.

The results of this study are in accordance with by Fond et al., who found an association between CRP levels and BMI $(p<0.001)$ when conducting research of 219 patients with both schizophrenia and schizoaffective disorders in Paris, France [11]. Research conducted by Boozalis et al. in the United States in 2018, for 106 patients, showed that HsCRP levels had a positive correlation with BMI $(r=0.29, p=0.004)$ [12]. In addition, researchers found that in their subjects, there was a significant difference between the HsCRP level in the group of overweight patients compared with the HsCRP level in the normal weight patient (1.62 \pm $0.09 \mathrm{mg} / \mathrm{L}$ and $0.56 \pm 0.08 \mathrm{mg} / \mathrm{L}, \mathrm{p}<0.001)$. In their research, Boozalis et al. also stated that a state of obesity or excess body weight was associated with an increase in the inflammatory process and the possibility of dyslipidemia in people with schizophrenia. According to Boozalis et al., effective interventions are needed to prevent weight gain in people with schizophrenia in hopes of preventing poor outcomes.

Research by Joseph et al. in the United States in 2015 stated that HsCRP was positively correlated with BMI ( $p=0.006 ; r=0.317)$ [13]. In the same study, Joseph et al. stated that there was a correlation between HsCRP levels and other hormones such as leptin, which also affects adiposity. Thus, in his research, it was also stated that anthropometric measurements, in this case, the BMI, can be useful, although it is limited to the number of factors that can influence it, such as differences in gender, ethnicity, and so on.

This study also shows that there is a statistically significant correlation between the HsCRP variable and the MoCA-INA score variable with a $p<0.001$ and $r=-0.743$. The results of this study are in accordance with Dickerson et al. in Maryland, Baltimore, the United States of 413 patients, which in their study, the authors found that patients with CRP levels $<5 \mathrm{mg} / \mu \mathrm{l}$ had higher cognitive scores than patients with CRP levels $\geq 5.0 \mathrm{mg} / \mu \mathrm{l}$ [3]. Although Dickerson et al. stated that it was still unclear for the mechanism by which CRP can affect cognitive function, the authors suggested that this may be related to the inflammatory process that occurs in the central nervous system. Researchers have linked environmental (HSV-1) and genetic (alpha lymphotoxin genotype) factors associated with cognitive impairment and linked it to CRP levels [14], [15].

Diyanoosh et al. in 2012 also found the same thing when conducting research in Iran, where among 75 patients, researchers found cognitive deficits were positively correlated with CRP levels ( $p<0.05 ; r=0.18)$. In their research, Diyanoosh et al. using mini-mental status examination to assess the cognitive function of the subject, in contrast to this study which used the MoCA-INA score to assess cognitive function in subjects. Diyanoosh et al. suggested a need to assess CRP in people with schizophrenia in general.

\section{Conclusions}

Increased pro-inflammatory activity such as HsCRP is thought to cause impaired cognitive function in people with schizophrenia. Since the increase in CRP levels is caused by an inflammatory process, it is therefore possible that using anti-inflammatory drugs may decrease the pathological effect of schizophrenia or even improve symptoms. However, further research is needed and should be able to consider the effective factors that may be associated with schizophrenia that can be identified.

As for the limitations and advantages of this study, researchers have attempted to use one measurement tool that is rarely used, and therefore very few studies have used the MoCA-INA score as a measurement tool so that this research is expected to be one of the references in conducting research using the MoCA-INA. Some limitations were, this research was still single centered. Researchers also had not included several epidemiological factors such as race, ethnicity, which can also determine the incidence of schizophrenia.

\section{References}

1. Tamminga CA. Introduction and Overview. In: Sadock VA, Kaplan RP, Sadock BJ, editor. Comprehensive Texbook of Psychiatry. $9^{\text {th }}$ ed. New York: Lippincott Williams and Wilkins; 2009. p. 1433-7.

2. Sadock BJ, Sadock VA. Introduction and overview. In: Kaplan and Sadock's Synopsis of Psychiatry Behavioral Sciences/Clinical Psychiatry. $10^{\text {th }}$ ed. Philadelphia, PA: Lippincott Williams and Wilkins; 2007. p. 468-97. https://doi. org/10.1097/00004850-198907000-00008

3. Dickerson F, Stallings C, Origoni A, Vaughan C, Khushalani S, Yang S, et al. C-Reactive protein is allevated in schizophrenia. Schizophr Res. 2013;143(1):198-202. https://doi.org/10.1016/j. schres.2012.10.041

PMid:23218564

4. SinghS, ChaudhuriKT.Role ofC-reactive protein inschizophrenia: An overview. Psychiatry Res. 2014;216(2):277-85.

PMid:24565000

5. Fan X, Golf DC, Henderson DC. Inflammation and schizophrenia. Expert Rev Neurother. 2007;7(7):789-96. PMid:17610386

6. Dimitrov HD, Braida N, Bass WC. The Link between Immune System Dysregulation and Schizophrenia; 2001. Available from: http://www.psichiatryctimes.com. [Last accessed on 06 Aug 2020].

7. Akanji OA, Ohaeri JU, Al-Shammri S, Fatania HR. Association of blood levels of C-reactive protein with clinical phenotypes in Arab schizophrenia patiens. Psychiatry Res. 2009;169(1):5661. https://doi.org/10.1016/j.psychres.2008.06.010 PMid:19619902

8. Diyanoosh N, Rezaei O, Masafi S, Nazeri A, Hoseynzade. Relationship of blood C-reactive protein (crp) level and cognitive deficit in patien with schizophrenia. Int J Res Intern Med Puclic 
Health. 2012;4:1785-92.

9. Newcomer JW, Fahnestock PA, Haupt DW. Medical health in schizophrenia. In: Kaplan and Sadock's Comprehensive Textbook of Psychiatry. $9^{\text {th }}$ ed., Vol. 1. Philadelphia, PA: Lippincot Williams and Wilkins; 2009. p. 1576-7.

10. Norlelawati AT, Kartini A, Ramli M, Norsidah K, Azizi WW, Tariq AR. Obesity in multiracial schizophrenia patients receiving outpatient treatment in a regional tertiary hospital in Malaysia. East Asian Arch Psychiatry. 2012;22(2):49-56. https://doi. org/10.1111/appy.12089

PMid:22714874

11. Fond G, Godin O, Llorca PM, Leboyer M. Abnormal C-reactive protein (CRP) levels in schizophrenia and schizoaffective disorders. Results from the FACE-SZ dataset. Eur Psychiatry. 2015;30S:S102-61. https://doi.org/10.1016/j. eurpsy.2015.09.213

12. Boozalis T, Devaraj $\mathrm{S}$, Okusaga OO. Correlations between body mass index, plasma high-sensitivity c-reactive protein and lipids in patients with schizophrenia. Psychiatr Q. 2019;90(1):101-10. https://doi.org/10.1007/s11126-018-9606-3

PMid:30315442

13. Joseph J, Depp C, Martin AS, Daly RE, Glorioso DK, Palmer BW, et al. Associations of high sensitivity C-reactive protein levels in schizophrenia and comparison groups. Schizophr Res. 2015;168(1-2):456-60. https://doi.org/10.1016/j. schres.2015.08.019

PMid:26341579

14. Dickerson F, Boronow J, Stallings C, Origoni A, Yolken R. The lymphotoxin Cys13Arg polymorphism and cognitive functioning in individuals with schizophrenia. Schizophr Res. 2007;89(13):173-6. https://doi.org/10.1016/j.schres.2006.08.015 PMid: 17029750

15. Dickerson FB, Boronow JJ, Stallings C, Origoni $A E$, Ruslanova I, Yolken RH. Association of serum antibodies to herpes simplex virus 1 with cognitive deficits in individuals with schizophrenia. Arch Gen Psychiatry. 2003;60(5):466-72. https:// doi.org/10.1001/archpsyc.60.5.466

PMid: 12742867 